\title{
The SAS Institute's Human Resources Practices in Diversity and Inclusion
}

\author{
Claudette J. Delapenha ${ }^{\circledR}$, Cristin Espinosa ${ }^{\circledR}$, Jhanelle Fabre ${ }^{(0)}$, Pricilla Facey Lemon ${ }^{(0)}$, \\ Nalubega Gibson ${ }^{(0)}$, Bahaudin G. Mujtaba (1)
}

Nova Southeastern University, Huizenga College of Business and Entrepreneurship, Fort Lauderdale, FL, USA

Email: rhett6.cd@gmail.com, cvalle@mynsu.nova.edu, Jhanelletfabre@gmail.com, lemon.economicsexplained@gmail.com,

nrosegibson@msn.com,mujtaba@nova.edu

How to cite this paper: Delapenha, C. J., Espinosa, C., Fabre, J., Lemon, P. F., Gibson, N., \& Mujtaba, B. G. (2020). The SAS Institute's Human Resources Practices in Diversity and Inclusion. Journal of Human Resource and Sustainability Studies, 8, 249-265. https://doi.org/10.4236/jhrss.2020.83014

Received: July 10, 2020

Accepted: August 8, 2020

Published: August 11, 2020

Copyright $\odot 2020$ by author(s) and Scientific Research Publishing Inc. This work is licensed under the Creative Commons Attribution International License (CC BY 4.0).

http://creativecommons.org/licenses/by/4.0/

(c) (i) Open Access

\begin{abstract}
Human resource management is a major influence on the way employees behave, their attitudes and overall performance. There are core strategies that need to be explored for a company to maximize their influence on the organization's overall performance. At SAS Institute, a leading provider of analytics software, exemplary human resource management is what the company prides themselves on and is recognized on a national level. This literature-based qualitative paper provides an in-depth assessment and analysis of the SAS' planning, recruitment, selection, employee development, compensation, performance management and employee relations to reveal what makes the organization supersede many of their competitors in human resource management practices of diversity and inclusion. Additionally, we highlight relevant strategies and the results of our SWOT analysis while further exploring areas for improvement of the institution. Modern managers and human resources professionals can benchmark many of the relevant diversities and inclusion practices in order to remain competitive in their own firms and industries.
\end{abstract}

\section{Keywords}

Diversity, Inclusion, SAS, SAS Institute, Best Practices in HR, Training, Employee Development

\section{Introduction}

Human resources management refers to the policies, practices, and systems that influence employees' behavior, attitudes, and performance toward ethical and sustainable practices that secure a competitive advantage over time in the industry and economy (Senathip, Mujtaba, \& Cavico, 2017; Tran, Tran, Nguyen, 
Mach, Phan, \& Mujtaba, 2020). Some of these practices include planning, recruiting, selecting, employee development, compensation, performance management, and employee relations. These strategies need to be considered by the company to maximize their influence on the organization's performance. $\mathrm{Hu}$ man resources management supports the company's performance by contributing to employees' and customer satisfaction, innovation, productivity, and development of a favorable reputation in the communities that the organization serves (Noe, Hollenbeck, Gerhart, \& Wright, 2017; Mujtaba, Cavico, \& Senathip, 2020).

SAS Institute is an American multinational developer of analytics software, headquartered in Cary, North Carolina. SAS develops and markets a suite of analytics software which helps access, manage, analyze, and report on data to aid in decision making. SAS Institute Inc. is a provider of business analytics software and services. The company's solutions portfolio includes analytics pro, customer intelligence 360, data management, enterprise miner, grid manager, visual analytics and statistics, curriculum pathways, foundation tools and software trials (SAS Institute, 2018). SAS also offers advanced analytics, artificial intelligence (AI) solutions, business intelligence and analytics, cloud analytics, customer intelligence, fraud and security intelligence, personal data protection, risk management, small and midsize business, and supply chain intelligence. It caters to many industries including automotive, banking, communications, education, financial services, government, health insurance, healthcare providers, hospitality and entertainment, insurance, life sciences, manufacturing, media, oil and gas, retail, and utilities. SAS operates across the Americas, Europe, the Middle East, Africa (EMEA) and Asia-Pacific (SAS Institute, 2018).

The SAS Institute exemplifies outstanding human resources management. It is the largest privately owned software firm in the world with over 14,000 employees. SAS has a proven track record of executing unique and strategic human resource management practices. These strategies have played a vital role in the organization's success and competitive advantage. Throughout the years, SAS has developed a special company culture and has refined a distinctive set of human resource management practices, which has greatly distinguished them from their competitors. For example, SAS applies the motivational approach to job design, which focuses on the job characteristics that affect psychological meaning and motivational potential, and it views attitudinal variables, such as satisfaction, as the most important outcomes of job design (Noe et al., 2017: p. 179). The human resources management team employs both "extrinsic" hygiene factors, such as exceptional benefits and an excellent work-life balance, as well as "intrinsic" motivators, such as job enrichment, recognition, advancement and growth (Ivancevich, Konopaske, \& Matteson, 2019: pp. 105-111). In fact, intrinsic motivation is the second most important principle within the SAS organization. According to the former vice president (VP) of American sales, Barrett Joyner, "the emphasis is on coaching and mentoring rather than monitoring and 
controlling. Trust and respect it's amazing how far you can go with that" (Pfeffer, 1998: p. 5). In addition to administering the motivational approach, the human resources management team has focused on and analyzed the best strategies for recruiting, selection, retention, company culture, compensation, benefits, and outsourcing to increase and maintain their competitive advantage. Effective human resources management has proven to enhance company performance by contributing to employee and customer satisfaction, innovation, productivity, and development of a favorable reputation in the organization's community (Noe et al., 2017). The SAS Institute has indeed achieved a high level of success and competitive advantage because they epitomize these exemplary human resources management strategies.

In the following sections, we will discuss the importance of strategic human resource practices at SAS, including their recruitment, selection, training, and employee relations. This will be followed by explaining how these HR practices provide firms like SAS a competitive advantage in the industry. Next, the paper discusses how SAS has retained industry recognition, while observing their strengths and opportunities in the marketplace along with how they mitigate some of the weaknesses and threats. Finally, the paper offers recommendations for all HR professionals and managers to effectively diversify their organizations and work practices in order to have an inclusive work culture.

\section{Strategic HR Practices}

Organizations must take a holistic approach to diversity and inclusion in the workplace. According to Ollapally and Bhatnagar (2009), the emergence of globalization has led to organizations intensifying their approach to managing diversity. The authors alluded to the fact that in the past diversity and inclusion was a reactive approach to respond to laws in place which required firms to include minority individuals in their workforce. However, firms are now seeing the benefits of diversity as a part of their strategy in gaining a competitive edge as it gives them access to a wide range of information, better decisions, better problem solving and more innovation (Ollapally \& Bhatnagar, 2009).

As defined by Ivancevich, J. M., Konopaske, R., \& Matteson, M. T. (2018), diversity refers to differences in age, ethnicity, gender, physical attributes, race, and sexual or affectional orientation and all these attributes make people different. Inclusion refers to creating an environment in which employees feel a sense of belonging, where they are mutually respected and they feel a sense of commitment from others (Noe et al., 2017). SAS firmly believes that a diverse and inclusive workforce is crucial for the company if they want to attract and retain top talent (SAS, 2020). Diversity and inclusion are applicable to areas such as recruitment and selection, training, and employee relations.

\section{Recruitment and Selection}

The recruitment and selection process within most organizations can be chal- 
lenging and overwhelming. With the possibility of hundreds of applicants trying to get one role, it is important for companies to have an organized process to ensure the best candidate is chosen. Recruitment is the process through which the organization seeks applicants for potential employment. Selection is the process by which it attempts to identify applicants with the necessary knowledge, skills, abilities, and other relevant characteristics that will help the company achieve their goals (Noe et al., 2017: p. 87). SAS has a high reputation in the information technology (IT) and software industry, thus making them highly desirable for job seekers.

Their strategic recruitment focuses primarily on the location of candidates, cultural fit, and employee referral. Additionally, the seven-step recruitment process implemented by SAS ensures that quality applicants are selected to be a part of the company. Employment opportunities are marketed through the company's website, job fairs and on third party job boards such as ZipRecruiter. With that, SAS does not utilize external recruiting agencies, the on-staff resources have done exceptionally well with hiring and job placement, therefore there is no need for external recruitment. The sources from which a company recruits prospective employees are a critical aspect of recruitment strategy (Breaugh, 2009). The type of person who may apply on a job board versus a job fair can vary greatly, which is another reason SAS sticks to "in-house" recruiters only. Due to high desirability many applications are received on a weekly basis. To help sort through them the company first focuses on recruiting candidates that are within close proximity to headquarters or have an interest in working in North Carolina. The reputation that SAS has maintained in the community as being a great place to work has aided in leveraging recruitment.

Within an organization that prides themselves on having strong culture, it is important that cultural fit is emphasized in the hiring and recruitment process. About $53 \%$ of new hires at SAS tend to come from employee referrals. The endorsements of the company and the role from a knowledgeable current employee have strong effects in the early recruitment process of candidates. To maintain the multidimensional culture that blends the variety of backgrounds, experiences and perspectives from employees SAS uses their seven-step hiring process to ensure that potential candidates will enhance the current culture through showcasing their talent and skills. The hiring process is as follows:

1) Application: the process is designed to be simple and transparent.

2) Review: the application will be reviewed by one of the recruiters.

3) Recruiter phone call: once identified as a potential candidate a member from the recruitment team will contact them and see if the candidate meets the minimum qualifications for the role.

4) Phone interview: this would be between the candidate and someone from the hiring team. The call will focus on technical and communication skills as well as job fit.

5) On-site Interview: focused on SAS values, job competencies and may in- 
clude a role-based activity or work sample.

6) Decision: interview team debriefs and decides.

7) Offer: YOU ARE HIRED!

What also sets SAS apart from most companies is that during their on-site interview (Step 5) there are three types of interviews that may be conducted: competency based, values based, and role based. The competency-based interview includes behavioral interview questions that are intended to gather a picture of one's past job experiences and to gauge how successful they were in previous roles. This is a situational interview, which is an interview procedure where applicants are confronted with specific issues, questions or problems. Situational interviews can be particularly effective when assessing sensitive issues dealing with the honesty and integrity of candidates (Bobko \& Roth, 2013). The value-based interview is to see if one's values align with the core values of the company which are "Authentic, Accountable, Curious and Passionate."

Lastly, there is the role-based activity, depending on which position is being applied for the candidate may be asked to give a presentation, solve a problem, or submit a writing sample. While this may seem like an intimidating process to some, one must remember that SAS prides themselves on employing the best and most dedicated candidates and this process is one that provides a thorough evaluation. Once the candidate has been selected, they are to attend the new hire orientation that will introduce the new employee to \#saslife.

\section{Training}

According to (Noe et al., 2017), training involves any planned activity that enables the learning of skills, knowledge, and behavior related to the job. While a company diversifies its workforce, it must ensure that employees feel included. It is therefore important that firms include diversity training in their HR practices. Diversity training refers to efforts made to learn about the diverse workforce with the hopes of changing employee attitudes about diversity (Noe et al., 2017). However, this is not sufficient, as the authors purported that employees must also be involved in making organizational decisions to achieve the short- and long-term goals of the organization.

SAS has several inclusion programs that provide training and support to employees such as the Veteran Employment, Training and Support program. This program provides service members, veterans, and spouses with the opportunity to experience a civilian corporate work environment through internships, outreach programs and career mentoring days. According to Sean Mobley, Senior Associate Systems Director (past US Army National Gardsman) "I could tell SAS was a great place to work since the beginning of the hiring process when I met employees at a hiring event. Once hired and called upon for military training, it was easy to talk about my military obligations with my manager. It felt great to know that I have the full support of my leadership, my team and the company. And even better, I now get the chance to play a part in veterans' outreach, help- 
ing to recruit veterans and bridge the gap in understanding military and civilian culture" (UK, 2020, para. 6).

Additionally, the company is aware that there are generational differences that exist that can ultimately affect the goals of the organization. According to Rajput, Bhatia, and Malhotra (2019), managers must understand the differences in work values, motivators, and leadership style preference for each generation. They must also be able to put in place measures that are equitable to prevent conflict across the various generations working together. SAS offers multigenerational training that helps everyone better understand the dynamics at play in today's workplace. The company believes that if everyone works together, recognizes, and respects the knowledge, skills, and experience of each generation, it helps the organization succeed and flourish.

\section{Employee Relations}

Noe and colleagues (2018) stated that relationships with employees can strongly affect a company's potential for gaining a competitive advantage. The authors further explained that companies can choose to treat their employees as an asset, or they can treat them as an expense. At SAS, CEO James Goodnight stated that "95\% of my assets drive out every day" (Kropp, 2015). According to Goswami, \& Kisho, 2018), employee inclusion is positively related to employee engagement. Employee engagement refers to the extent to which employees are fully involved in the job and their level of commitment to the organization (Mujtaba, 2014). Managing a diverse workforce becomes important if managers want to keep employees engaged. Ollapally and Bhatnagar (2009) noted that in organizations where diversity is not managed or recognized, employees tend to feel cut off from a social network. They tend to feel as though there would have been a breach in a psychological contract to diversity leading to increased absenteeism and high turnover. However, this is not evident as SAS.

At SAS there are many employees that have been working for the institution for over 20 years, indicating that they are satisfied and committed to the organization. The tenure and longevity of employment is often a leading indicator of workers' job satisfaction and loyalty to the organization; consequently, these senior and experienced employees can serve as positive role models and mentors for new comers. In 2018, Nigel Armstead, Account Executive at SAS stated, "Since I first interviewed with SAS in 1998, I have had nothing but positive experiences. I can be myself at work and feel accepted, valued and included." With the level of inclusion felt by the employees the level of engagement and commitment to the firm increases as there are excellent employee relations at the firm. With the varied benefits, training, and compensation packages offered by SAS, employees find it hard to leave because they are given the "royal treatment" (SAS Institute, 2020, para. 7).

According to SAS (2020), a diverse and inclusive workforce fosters a more creative and innovative workplace. They believe that the backgrounds, expe- 
riences and perspectives of all its employees create a unique multidimensional culture where everyone is respected for their contributions and abilities. This helps to build positive and sustainable employee relations as employees feel appreciated for their contributions to the development and success of the business. SAS has a number of inclusion programs that build employee relations, such as the Women's Initiative Network that empowers and inspires women of all ages in order to foster a pipeline of talents across the organization. This has resulted in the company being awarded, year after year, as best workplace to work for women by Fortune Magazine. The Black Initiatives Group (BIG) is another initiative aimed at inclusion. This group works to offer empowering STEM education opportunities to employees, students and graduates who self-identify as black, African, African-American, West Indian, indigenous, American Indian, Afro-Latinx and others.

\section{Competitive Advantage: HR Practices}

Recruitment, selection, motivation, training, and retention of talent are very important components in the continued success of SAS, particularly since their business requires frequent development and innovation of their software products. Their human resources management department has long recognized that developing and retaining top talent is the key to further software advances. In an interview with Glassdoor.com, Jennifer Mann, Executive VP \& Chief Human resources officer explained her philosophy, "At SAS, our goal is to offer meaningful work for our employees, an empowering management philosophy, and a world-class work environment that includes services and benefits to make employees' lives easier at work and in their personal lives. This allows them to be motivated, creative, and innovative in our software development. It's critical for us to provide a workplace that incentivizes great talent" (SAS Institute, 2020, para. 5). This philosophy has given SAS a great competitive advantage over their competitors.

Training consists of a two-week orientation program, hosted by senior management, to immerse new employees into the company culture. This company culture is one of loyalty with happy employees, positive attitudes, teamwork, mutual respect, and cooperation. James Goodnight, the CEO, explains that the purpose of gaining such loyalty is not to win awards, but that the culture at SAS provides the company with a powerful competitive edge. "It turns out that doing the right thing, treating people right, is also the right thing for the company," says Goodnight (Fishman, 2000: p. 38).

As for compensation, base salaries are very competitive and revised regularly. Bonuses are awarded once a year based on performance; however, they are unstructured. Goodnight has stated that there is "no formula" to their bonus structure and that he ultimately decides bonuses for that year based on how he feels (Pfeffer, 1998). There is also no commission offered. Barrett Joyner believes commission creates a high pressure, stressful environment. He states, "We have 
sales targets, but mostly as a way of keeping score. I want to make the numbers, but I want to make them in the right way" (Pfeffer, 1998: p. 7). There is very little turnover, thanks to job enrichment, meaning that employees are frequently moved around to other departments with varying levels of authority and responsibility. Joyner also states, "The firm almost never loses someone to competition. They lose people because of life changes, like a spouse relocating" (Pfeffer, 1998: p. 8). These objectives have supported the company in meeting their strategic objectives to attract and retain top workers to the organization.

Gaining a competitive advantage is imperative for any company to survive. To compete at the top, organizations must constantly devise innovative ways to utilize resources more efficiently and discover novel ways to acquire new customers (Dixon, 2019). SAS is the leader in analytics over their biggest competitor IBM, not only because they offer innovative software and specialized services, but also because they have gained the trust of their clientele through exceptional customer service. Because SAS retains, develops, and motivates top talent so efficiently, their employees have a proven track record of successfully inspiring customers, in addition to engaging industry analysts for their recommendations on their software, messaging and other market and competitive information. In turn, these analysts offer valuable advice and research, through their publications, events, and consulting projects, to companies that are comparing SAS to other competitors and weighing options for their technology purchases (SAS Institute, 2020). Aside from offering top-notch software and services, because SAS has trained, developed, and retained the best employees in their industry who are skilled at building customers' trust and loyalty, they have earned a significant competitive advantage over IBM and other industry competitors.

\section{HR Concepts: Best Practices \& Awards}

The SAS Institute's best practices are meeting their strategic objectives to attract workers to their company and then get them to stay long enough to obtain some return on their investments. So, there are advantages and disadvantages associated with different workforces and organizations that survive and thrive to find the best match between the workers they need and the strategy they employ to compete in the market such as SAS (Noe et al., 2017). SAS Institute has many best practices that they use as a competitive advantage. CEO James Goodnight believes in giving SAS staff everything they need to do a good job, which includes the peace of mind of having their young children close at hand. SAS cafeterias have highchairs and parent-employees are free to take their children out of daycare and bring them to lunch. This practice helps to improve performance (Fishman, 2000).

In a competitive business where employees leave from company to company in search of richer stock options and where companies build staffs of consultants to avoid overhead, Mr. Goodnight has created the opposite: a culture of loyalty. One of the best practice SAS offers is the staff benefits. The company's main campus offers not only low-cost day care ( $\$ 250$ a month as of July 2020) but also 
free access to a 36,000-square-foot gym, a putting green, sky-lit meditation rooms, and the services of a full-time in-house elder-care consultant. There is a pianist in the cafe at lunchtime and all the free juice and soda employees want. The perks and benefits ensure that employees experience no distress that could lead to poor performance. Among the unusual benefits like childcare centers, certified doctors and nurses, elderly care, private offices, gaming facilities, etc., employees were also provided with infinite amounts of days as sick leave, and only had to work 35 hours a week with open flexibility (ICMR, 2020). Additionally, the company provided the same benefits for executives and workers, which is unusual in many companies. For example, SAS had no reserved parking spaces or dining halls for their senior managers. Because of SAS's unique culture and employee-centric management, the company attracted loyal employees who played a big role in certifying the company's customers and achieving long-term relationships with them. Consequently, SAS has had a lower employee turnover rate than the industry average. In recent years, numerous competitive companies like IBM, Oracle and SAP joined the software market; several professionals mentioned that these companies are looking for skilled candidates within the software field and SAS employees are the main target (ICMR, 2020). Additional benefits include exceptional healthcare (domestic partners included), a 7500 square-foot medical facility on site, two family practice physicians, a physical therapist, massage therapist, and a mental health nurse, and a 35-hour workweek.

Back in 2008 when the recession period occurred, with SAS being the exception, many software companies announced layoffs and had significant benefit reductions in the packages offered to their employees. Goodnight, however, encouraged his staff to spend carefully in order to control costs (ICMR, 2020). With the assurance of job security during the recession period, employees gave it their best effort so as to make a remarkable profit in 2009, maintaining the 33 -year track record in achieving and maintaining the projected profit as SAS (ICMR, 2020). Additionally, meetings were held on video conferences which led to a reduction in their travel expenses.

SAS Institute does not believe in outsourcing. Outsourcing is a company's use of an outside organization for a broad set of services. This is a logical choice when a firm simply does not have certain expertise and is not willing to invest time and effort into developing it (Noe et al., 2017: p. 204). However, outsourcing contradicts the time and effort SAS invests into developing their own employees, therefore the people working in the healthcare, gym, daycare, and food service facilities are all full-time SAS employees. SAS outsources almost nothing and uses very few contracted workers, nor do they use contract programmers nor programmers provided by temporary help agencies. Additionally, SAS does not outsource programming from facilities offshore. According to Barrett, "if you want something done right, own it and control it." Barrett believes that most companies outsource to save on costs, however this usually results in lower qual- 
ity. SAS is much more focused on people development and less focused on short-term costs (Pfeffer, 1998: p. 11).

The SAS Institute has been recognized for its outstanding and unique work culture, as well as its innovative ideas, which give it a significant competitive advantage over other corporations. In terms of employee royalty, what really differentiates SAS from other companies is its unusual perks and benefits that exceeds employee's expectations. Employee perks and benefits are based on employees' needs which are identified through daily surveys and feedback (ICMR, 2020).

\section{Awards}

In 2017, SAS was named one of the 2017 Best Workplaces for Diversity by Great Place to Work and Fortune. Per Michael Bush, the CEO of Great Place to Work, this was because they "find ways to connect with each and every employee, listening to their challenges and building on their talents" (SAS Institute, 2020, para. 3).

In 2019 the SAS institute was recognized as one of the top 10 best workplaces in the UK (UK, 2020). These rankings were based on the company's employee surveys, as well as comprehensive evaluations and procedures, which show that the SAS Institute strives to provide their employees with an environment that recognizes and celebrates great work. Keeping their employees happy not only keeps their employees satisfied, but it motivates them to go above and beyond in serving their customers. According to SAS VP Charles Seabury, "Everybody knows that motivated, passionate and engaged employees are the key to an organization's long-term success and resilience" (UK, 2020, para. 4).

Moreover, this year SAS CEO Jim Goodnight was awarded the "CEO Great Place to Work for All Leadership Award” for the year 2020 (NC, 2020). This award celebrated his consistent commitment and dedication to his employees, and for providing his staff with an atmosphere where they can reach their greatest potential as workers. The general strengths, weaknesses, opportunities, and threats (SWOT) analysis of SAS is depicted Table 1.

We know that higher salaries, better bonuses, and favorable employee benefits from competitors can always be seen as threats to employee retention. At SAS, some of their employees have said that they received less pay in contrast to other software companies (ICMR, 2020). As a result of SAS offering lower pay, several employees were dissatisfied with the company citing difficulty in receiving promotions, and decreased salary than the industry average (ICMR, 2020). Of course, certain companies like IBM, Oracle and SAP have become big players in the software market; as such, they can easily "steal" experienced professionals from SAS as these companies would be looking for skilled professionals. Consequently, we recommend that SAS managers regularly assess the market value of their essential employees and adjust salaries and bonuses as relevant in order to retain their best talent and avoid dysfunctional employee turnover. 
Table 1. SAS Analysis through the SWOT Matrix.

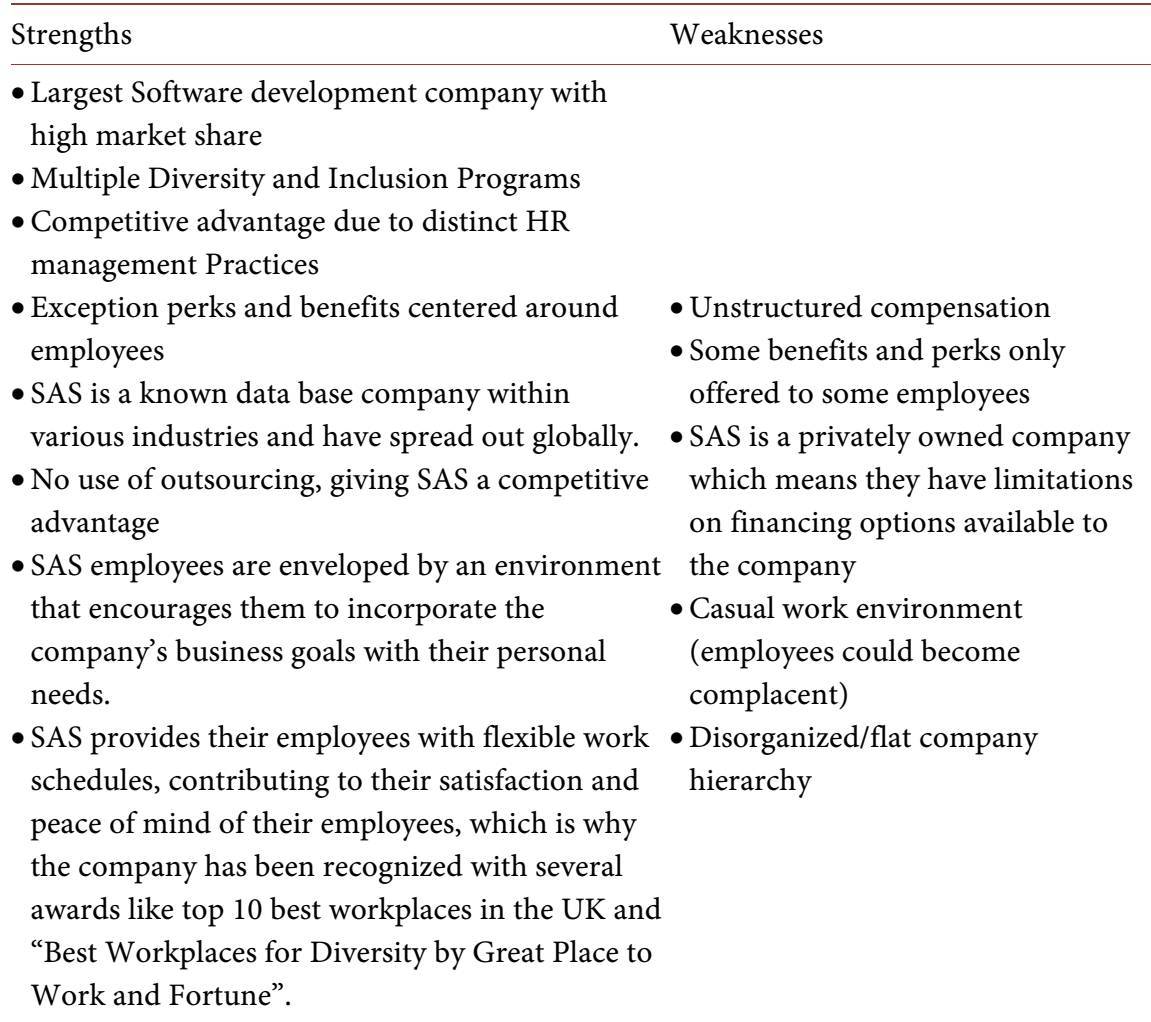

Opportunities Threats

- Due to its continuous expanding market, SAS has

- Competitors with better the opportunity to expand as much as its profits allow it to invest. Its technological demand is fundamentally infinite as of now.

- SAS has great opportunities with consistently expanding its geographical locations.

- SAS's growth and openness to diversity has permitted it to expand internationally.

- Structuring of performance management while maintaining employee management relationships/conversations.

- Innovation resulting from a diverse workforce

- Clear and defined path for employee growth

- Stronger and more defined pay/bonus/incentive structure

compensation and bonus' for employees

- Ultimate Software which also centers their perks and benefits around employees. This creates the possibility of losing talented employees

- SAS competes with companies such as IBM, Microsoft, Salesforce and many others. So, the fact that these competitors are well established and have stronger presence, could cause SAS to lose revenue - Competitors offering a clear path for growth and development

\section{Recommendations}

The significance of understanding certain best practices that have made these companies, like SAS, to be one of the best places to work for in the United States is that managers can benchmark the relevant strategies and apply them to their own departments and organizations. Even though these firms are competitive, their managers cannot relax or become complacent and self-righteous; as such, human resources professionals and managers must regularly and continuously 
improve their work practices in order to be on the leading edge of their industries through the effective inclusion of their diverse human capital. In order to understand the changing needs of the employee, managers must keep their finger on the worker's pulse. These managers must develop an extensive database on their employees and learn everything they can about the changing needs, desires and expectations of each worker. By knowing the needs of their employees, managers and companies are better able to meet and exceed their expectation, thus inducing them to do more for the business and bring their professional colleagues and family members along. As said by Mahatma Gandhi, "The best way to find yourself is to lose yourself in the service of others". Human resources professionals and managers must see themselves as being in the business of serving others, such as their colleagues, employees, suppliers, vendors and customers.

Even though SAS has a unique culture there are a few recommendations that can help improve and sustain their success. The SAS Institute should alter some of their strategies to be more structured, such as compensation. Goodnight, for example, stated that there is "no formula" to their bonus structure and that he ultimately decides distributing bonuses for the year based on how he feels (Pfeffer, 1998: p. 7). However, a more defined bonus system would further motivate employees to perform to their highest potential. Especially, because some employees feel their salaries could be better. Even though SAS offers competitive employee benefits which makes up for the gap in their salary, the company should address those employee concerns accordingly. Pay structure plays a vital role in implementing fair human resources strategies. First, a high level of pay, incentives, and/or benefits relative to that of competitors can ensure that the company attracts and retains high-quality employees. Secondly, by tying a pay for performance structure, the company can motivate specific activities and extract high levels of performance from employees (Noe et al., 2017: p. 90). This also relates to the expectancy theory, which states that "employees are more likely to be motivated when they perceive their efforts will result in successful performance and, ultimately, desired rewards and outcomes" (Ivancevich et al., 2019: p. 113).

Performance management and appraisals should be more structured as well, as they are part of the HR planning process. While the frequent yet casual manager/employee conversations and coaching strategies that SAS executes are beneficial, more structured documentation is essential for legal purposes as well, especially when it comes to the time to terminate an employee. Structured documentation also ensures that every employee is held accountable for achieving their goals and certifies that each employee is advancing properly, allowing ample opportunity for the manager to focus on coaching and development. Formal annual appraisals compare results to the initial goals, which allows both the manager and employee to analyze what worked and what did not (Noe et al., 2017: pp. 209-210). 
As it pertains to compensation, SAS employees are currently happy with their healthcare, however, the recommendation is for the company to look at an Employer Provided Healthcare system. This would be an even bigger motivational factor than monetary bonuses. Based on research, most people on employer sponsored healthcare insurance appear to be satisfied with the coverage they get (Dolan, 2018). A survey by America's Health Insurance Plans, an insurance industry group, found that 71 percent of respondents were satisfied with their plans, compared with just 19 percent who were not satisfied. An independent survey by Gallup came up with similar results, finding 69 percent of people in employer sponsored plans to be satisfied. A study by the Employee Benefit Research Institute found that 50 percent of workers were extremely or very satisfied with their own Employer Sponsored Insurance plans, with another 39 percent somewhat satisfied (Dolan, 2018). Job-linked health benefits first became widespread during World War II, when American firms faced both a labor shortage and a wage freeze. Desperate to attract employees, they started giving out benefits like health insurance instead of cash raises. SAS Institute employees are likely to agree it would be an excellent idea which can add even more motivational value.

Another recommendation for SAS Institute is to sustain the process of their leadership style and decision-making process. SAS's emphasis is on employee motivation and client relationship building. SAS continues to move in a supportive way to motivate and support their employees and customers at a very high level. This importance shows that SAS has a supportive and strong foundational decision-making process. The company's actions highlight the Vroom-Jago Leadership Model. According to Vroom and Yetton, this normative model provides guidelines that leadership can use to make decisions. A proactive way of reacting to the Covid-19 pandemic and to encourage and motivate employees, demonstrates real leadership abilities. The Vroom-Jago Leadership Model approach assumed that there is no one single leadership style but leaders must be flexible enough to change as situations change (Ivancevich, Konopaske, \& Matteson, 2018).

Vroom and Yetton made some assumptions in the model about leadership style. To understand this model, it is important to consider three critical components: 1) specification of the criteria by which decision effectiveness are judged, 2) a framework for describing specific leader behaviors or styles, and 3) key diagnostic variables that describe important aspects of the leadership situation (Ivancevich, Konopaske, \& Matteson, 2018). SAS Institute leadership style exhibits the decision and effectiveness of the Vroom-Jago leadership model. The decision quality and subordinate commitment refer to the extent to which decision impacts job performance. SAS strategies for employee's motivation would impact job performance.

According to Kirby and Richard (2000), when the workforce is diverse it gives an organization a competitive edge and performance tends to increase. Organi- 
zations must therefore design recruiting strategies to attract diverse applicants. This will allow the organization the opportunity to have a global perspective as it embraces different cultures and ethnic groups.

In building diversity and ensuring inclusion organizations can make the effort to train employees to be more sensitive to each other. Grensign-Pophal (1997) stated that when individuals are averse to the opinions and viewpoints of others it prevents productivity and creativity. As such, organizations must train employees to be accepting of the viewpoints of others and help them to be aware of their own biases. They can therefore make use of simulation exercises that can be an effective training tool. Individuals can be placed in various situations to enact how they would behave in given scenarios related to a diverse workforce and dealing with any misconceptions as they arise.

Candidates appreciate feedback when they are not selected for a job. Due to SAS' multi-step hiring process, it would be disheartening as well as confusing for some candidates to go through all of that and not know why they did not make it to the seventh step. One recommendation would be to give candidates who were not selected a follow up call or email, highlighting their strengths but offering constructive criticism on areas for improvement. The 2018 North American Talent Board Candidate Experience Benchmark Research Report, found that $69.7 \%$ of candidates receive no feedback after being rejected during the screening and interviewing stages of their job candidacy. Another $53.5 \%$ of job candidates do not receive feedback after the interviewing stage. Implementing this will allow for SAS to go above and beyond what other companies are doing and set the golden standard.

\section{Summary}

Human resource management is a critical endeavor with which organizations can maximize their influence on performance. The SAS Institute stands as a strong example of human resource management, with a proven track record of executing unique and strategic human resource management practices. This has allowed for the development of a special organizational culture that distinguishes them from their market competition. In the modern global landscape, diversity and inclusion provide a proven competitive advantage (Ollapally \& Bhatnagar, 2009), and a strong firm is one that is diverse across all levels, including age, ethnicity, gender, and sexual orientation. The SAS Institute places a high value on having an inclusive workforce and strives to retain and attract top talent (SAS, 2020). In selecting talent, the organization considers not only aptitude and typical resume elements, but also the location of the candidate, cultural fit, internal promotion, and employee referrals in a distinct seven-step recruitment process.

A strong organizational culture is one in which every employee feels included, engaged, and valued without much negative stress (Tran, Tran, Nguyen, Mach, Phan, \& Mujtaba, 2020). The SAS Institute training program focuses on assisting 
present as well as new staff members in understanding diversity and its positive impact on team efforts. One such inclusion program employed by the organization includes veteran employment, training, and support. In addition, attention to generational differences is a focal element of the SAS Institute. Valuing a diversified culture is what builds relationships with employees and employee relationships with each other. The organization's CEO states that $95 \%$ of his assets leave each day (Kropp, 2015), illustrating his belief that the organization's true value lies in its employees. Other organizations, particularly those utilizing a classic organizational paradigm of top-down authoritative control, attempt to influence and manipulate through fear of losing one's position. The SAS Institute, though relatively new, has employees that have been employed with the company for more than 20 years, demonstrating high job-satisfaction and commitment. In the modern era, where employees often do not retire from the same organization that they began working for, this is an impressive feat and testament to the methods promoted by the SAS Institute.

The nature of the SAS Institute requires that it be innovative and make frequent developments. Incentivizing great talent has given them a competitive advantage. Understanding the needs of the staff and appreciating the staff is paramount. The organization's low-cost day care, free gym access, sky meditation rooms, elder care, pianists at lunchtime and free juice and soda for staff members are just some of the ways they have accomplished this goal. Though there are several things that the organization is doing right, there are some key areas in which they can improve. One such area was identified as their bonus structure having no objective formula. This creates the potential for unfair or mysterious bonuses to manifest, thereby causing possible confusion and division amongst the staff. Though all organizations have room for improvement, the SAS Institute is a strong model for understanding employee relationships in the $21^{\text {st }}$ Century.

This study was limited in scope to understanding and acknowledging some of the best practices at SAS in diversity and inclusion. While we admit that effective diversity and inclusion practices do heavily contribute to the success of any organization, a firm's success is not limited to these variables alone. There are other strategies and best practices like technology, knowledge management, marketing, financial investments, cross-cultural expansions, total quality management (TQM), kaizen, etc. that help companies grow and become leaders in their industries. As such, future researchers should investigate other relevant variables that can serve as best practices for a firm's human resource professionals and managers in becoming the best places to work for locally, nationally and globally around the word.

\section{Conflicts of Interest}

The authors declare no conflicts of interest regarding the publication of this paper. 


\section{References}

Bobko, P., \& Roth, P. L. (2013). Reviewing, Categorizing, and Analyzing the Literature on Black-White Mean Differences for Predictors of Job Performance: Verifying Some Perceptions and Updating/Correcting Others. Personnel Psychology, 66, 91-126. https://doi.org/10.1111/peps.12007

Breaugh, J. A. (2009). Recruiting and Attracting Talent: A Guide to Understanding and Managing the Recruitment Process.

https://www.shrm.org/hr-today/trends-and-forecasting/special-reports-and-expert-vie ws/Documents/Recruiting-Attracting-Talent.pdf

Dixon, M. (2019). Data Analytics and Competitive Advantage-The Correlation. Selerity. https://seleritysas.com/blog/2019/05/26/data-analytics-and-competitive-advantage-thecorrelation

Dolan, E. (2018). What's Wrong with Employer Sponsored Health Insurance. Niskanen Center.

https://www.niskanencenter.org/whats-wrong-with-employer-sponsored-health-insura nce

Fishman, C. (2000). SAS Institute Isn't an Employer-It's a Provider. Employees Don't Have to Worry about Balancing Work and Life Because They're One and the Same. Workforce Costa Mesa, 3, 38.

Goswami, S., \& Kishor, B. (2018). Exploring the Relationship between Workforce Diversity, Inclusion and Employee Engagement. Drishtikon: A Management Journal, 9, 65-89.

https://www.academia.edu/40478283/Exploring the Relationship between Workforce Diversity Inclusion and Employee Engagement

ICMR, IBS Center of Management Research (2020). Culture at SAS Institute-The World's Largest Private Software Company.

https://www.icmrindia.org/casestudies/catalogue/Human\%20Resource\%20and\%20Org anization\%20Behavior/Culture-at-SAS-Institute-Excerpts.htm

Ivancevich, J. M., Konopaske, R., \& Matteson, M. T. (2018). Organizational Behavior \& Management (11th ed.). New York: McGraw-Hill.

Ivancevich, J. M., Konopaske, R., \& Matteson, M. T. (2019). Effective Managers Understand Organizational Behavior. In Organizational Behavior \& Management (11th ed.). New York: McGraw-Hill.

Kirby, S. L., \& Richard, O. C. (2000). Impact of Marketing Work-Place Diversity on Employee Job Involvement and Organizational Commitment. The Journal of Social Psychology, 140, 367-377. https://doi.org/10.1080/00224540009600477

Kropp, L. (2015). SAS, “Royal Treatment”(Video File). https://www.youtube.com/watch?v=ki4t3ze0454

Mujtaba, B. G. (2014). Managerial Skills and Practices for Global Leadership. Pace, FL: LEAD Academy.

Mujtaba, B. G., Cavico, F. J., \& Senathip, T. (2020). Strategies for Personal, Organizational and Professional Leadership Success. Scientific Journal of Research \& Reviews, 2, 1-10. https://irispublishers.com/sjrr/volume2-issue3.php https://doi.org/10.33552/SJRR.2020.02.000538

NC, C. (2020). SAS' Jim Goodnight Honored with CEO Great Place to Work for All Leadership Award.

https://www.sas.com/en th/news/press-releases/2020/march/2020-gptw-leadership-aw ard-goodnight.html 
Noe, R. A., Hollenbeck, J. R., Gerhart, B. A., \& Wright, P. M. (2017). Human Resource Management: Gaining a Competitive Advantage (10th ed.). New York: McGraw-Hill Education.

Noe, R. A., Hollenbeck, J. R., Gerhart, B. A., \& Wright, P. M. (2017). Human Resource Management: Gaining a Competitive Advantage (11th ed.). New York: McGraw-Hill Education.

Ollapally, A., \& Bhatnagar, J. (2009). The Holistic Approach to Diversity Management: HR Implications. Indian Journal of Industrial Relations, 44, 454.

Pfeffer, J. (1998). SAS Institute: A Different Approach to Incentives and People Management Practices in the Software Industry. Harvard Business Review, Publication HR-6.

Rajput, N., Bhatia, S. P., \& Malhotra, B. (2019). Generational Diversity: An Exploratory Study on Managing Multigenerational Workforce, a Sustainable Solution. Global Journal of Enterprise Information System, 11, 37-43.

SAS Institute (2020). Diversity and Inclusion: Embracing Multiple Cultures and Identities. https://www.sas.com/en ph/company-information/diversity/multicultural.html

SAS Institute Inc. (2018). MarketLine.

https://www.ebsco.com/

Senathip, T., Mujtaba, B. G., \& Cavico, F. J. (2017). Policy-Making Considerations for Ethical and Sustainable Economic Development. Economy, 4, 7-14.

https://doi.org/10.20448/journal.502.2017.41.7.14

Tran, C. T. H., Tran, H. T. M., Nguyen, H. T. N., Mach, D. N., Phan, H. S. P., \& Mujtaba, B. G. (2020). Stress Management in the Modern Workplace and the Role of Human Resource Professionals. Business Ethics and Leadership, 4, 26-40.

https://armgpublishing.sumdu.edu.ua/journals/bel/volume-4-issue-2/article-3

UK, M. (2020). SAS Recognized as One of the Top 10 Best Workplaces in the UK. https://www.sas.com/en gb/news/press-releases/2020/may/sas-recognised-as-one-of-th e-top-10-best-workplaces-in-the-uk.html 